\title{
Airways obstruction and uneven gas distribution in the lung
}

\author{
R. MA L M B ER G, B. S I MON S SON, A N D E. B ER G L U N D \\ From the Pulmonary Function Laboratory, Göteborg University Lung Clinic, Renströmska Sjukhuset, \\ Göteborg, Sweden
}

There may be a relationship between pulmonary airways obstruction and uneven distribution of inspired gas in the lung. The former can be assessed from measurement of the timed expiratory volume, and the latter from the single breath nitrogen test. If airways have peripheral obstruction and hence a resistance to air flow which is greater than normal, any local differences in resistance will cause uneven filling of different parts of the lung (Otis, McKerrow, Bartlett, Mead, McIlroy, Selverstone, and Radford, 1956). Such uneven filling can be detected with the single breath nitrogen test (Fowler, 1952) provided the lung empties asynchronously. Thus it is theoretically likely that there will be a correlation between airways obstruction and uneven gas distribution, and the purpose of this paper was to study how often an abnormal F.E.V.\% $\%=\frac{\text { F.E.V.1.0 }}{\text { F.V.C. }} \%$ (Gandevia and Hugh-Jones, 1957) coexisted with an abnormal single breath nitrogen test in patients with different lung disease.

\section{MATERIAL}

Measurements of both forced vital capacities and single breath nitrogen tests were performed on 264 patients referred to this laboratory from 1958 to 1960 . Most of the patients were admitted to the lung clinic. There were 188 men, 163 of whom were older than 35 years. Most of the 76 women were between 35 and 55 years of age.

The most common diagnoses were bronchitis, with or without airways obstruction, tuberculosis, tumour, and 'disseminated lung disease' (Table). For nomenclature, see Ciba Guest Symposium (1959) and Fletcher (1961). The 'disseminated lung disease' group consisted of patients with sarcoidosis, idiopathic or post-radiation fibrosis, and pneumoconiosis. Since our interest was mainly focused on bronchitis, tuberculosis, and irreversible airways obstruction, patients with a combination of different diseases were referred to these three groups. As a rule the patients were listed under the diagnosis which was clinically most important.

The tuberculosis group included a few patients with known upper lobe bronchiectasis. The original disease in the group where pneumonectomy was performed was tuberculosis or tumour, but the remaining lung was supposed to be normal. The 'extrapulmonary thoracic disease' group consisted of patients with pleuritis and funnel chest.

\section{METHODS AND PROCEDURES}

SPIROMETRY A spirometer with a very light spirometer bell, a $50 \mathrm{~mm}$. wide spirometer-to-mask tubing, and a highly damped water system was used for forced expiratory spirograms (Bernstein, d'Silva, and Mendel, 1952). The tests were done by a trained technician. After careful instruction at least four forced expirations were recorded on a kymograph with a speed of $50 \mathrm{~mm}$./second. The largest forced expired volume in one second (F.E.V.1.0) was measured and expressed in per cent of the maximal forced vital capacity (F.V.C.), giving the F.E.V. $\%\left(=\frac{\text { F.E.V.1.0 }}{\text { F.V.C. }} \times 100\right)$ which was used as an index of airways obstruction (Drutel and Dechoux, 1952; Thomson and Hugh-Jones, 1958).

'SINGLE BREATH NITRCGEN' TEST Nitrogen concentrations in the mouth-piece were continuously measured by a nitrogen meter and recorded together with the expired lung volume on a direct-writing ink-jet recorder ${ }^{1}$. The test was done in a standardized manner (Kjellmer, Sandqvist, and Berglund, 1959). It was conducted by a doctor with the subject in the sitting position. Starting from resting expiratory level the subjects inspired ' 1 litre' $(0.9$ to 1.3$)$ of oxygen, and during the following expiration nitrogen concentration and expired volume were simultaneously recorded. Care was taken to limit the pause between inspiration and expiration. As a rule five curves were obtained with three- to five-minute intervals.

No patient was included with less than three acceptable curves. A few patients, who could not perform the test due to small vital capacities, were not included in this material. The nitrogen gradient was calculated as the difference between the nitrogen concentrations at expired volumes of 1,250 and $750 \mathrm{ml}$. B.T.P.S. (Kjellmer et al., 1959). The arithmetic mean of three to five values was given as the index of uneven gas distribution within the lungs (Sandqvist and Kjellmer, 1960). In 25 patients, selected at random, the S.D. for five measurements was

${ }^{1}$ Mingograf, Elema Co. 
0.4 to $2.5 \% \mathrm{~N}_{2}$ (average $1.2 \%$ ) with $\mathrm{N}_{2}$-gradients of 1.0 to $11.7 \%$; this gives a mean coeff.cient of variation of $22 \%$.

STATISTICS F.E.V. $\%$ and $\mathrm{N}_{2}$-gradient were correlated both for the total material and within groups with different lung diseases. Correlation coefficients were calculated for every group (Table) and tested for level of significance, using the t-test. The borders between normal and pathological values were obtained from a normal population studied in this laboratory (Sandqvist and Kjellmer, 1960; Berglund, Birath, Bjure, Grimby, Kjellmer, Sandqvist, and Söderholm, 1963); they are defined as two standard deviations lower limit for F.E.V. $\%$ and $95 \%$ conf dence upper limit for $\mathrm{N}_{2}$-gradient.

\section{RESULTS}

In the Table are shown the relative frequencies of pathological and normal $\mathrm{N}_{2}$-gradients in the patients with pathological and normal F.E.V.\%, respectively. In the bronchitis, irreversible airways obstruction, and tuberculosis groups, the patients with a pathological F.E.V. $\%$ showed a high incidence $(=2 / 1)$ of pathological $\mathrm{N}_{2}$-gradient; this high incidence of pathological $\mathrm{N}_{2}$-gradients was not present when the F.E.V.\% was normal. The F.E.V. $\%$ and $\mathbf{N}_{2}-$ gradient values are plotted in Fig. 1. The values show a wide spread. The correlation coefficients for the bronchitis and tuberculosis groups, assuming a normal distribution of the values, were calculated to be 0.83 and 0.50 , respectively. The coefficients of correlation were highly significant $(P<0.001)$ in these two groups.

In the bronchitis group 57 subjects had a pathological F.E.V.\%. Thirty-two per cent of these subjects (18/57) had a normal $N_{2}$-gradient, while in the non-obstructive group of bronchitics 33\% (14/42) had a pathological $\mathbf{N}_{2}$-gradient. In the tuberculosis group similar figures were obtained; thus $29 \%$ (15/51) with a low F.E.V. $\%$ had a normal $\mathrm{N}_{2^{-}}$ gradient; $37 \%(6 / 16)$ with a normal F.E.V. $\%$ had pathological distribution tests.
FIG. 1. Relation between $N_{2^{-}}$ gradient and F.E.V.\% values in four patient groups. In the lower right quadrant are the normal borderlines for the oldest and youngest age groups, respectively. Assuming a normal distribution of the values, a 'regression line' is constructed.

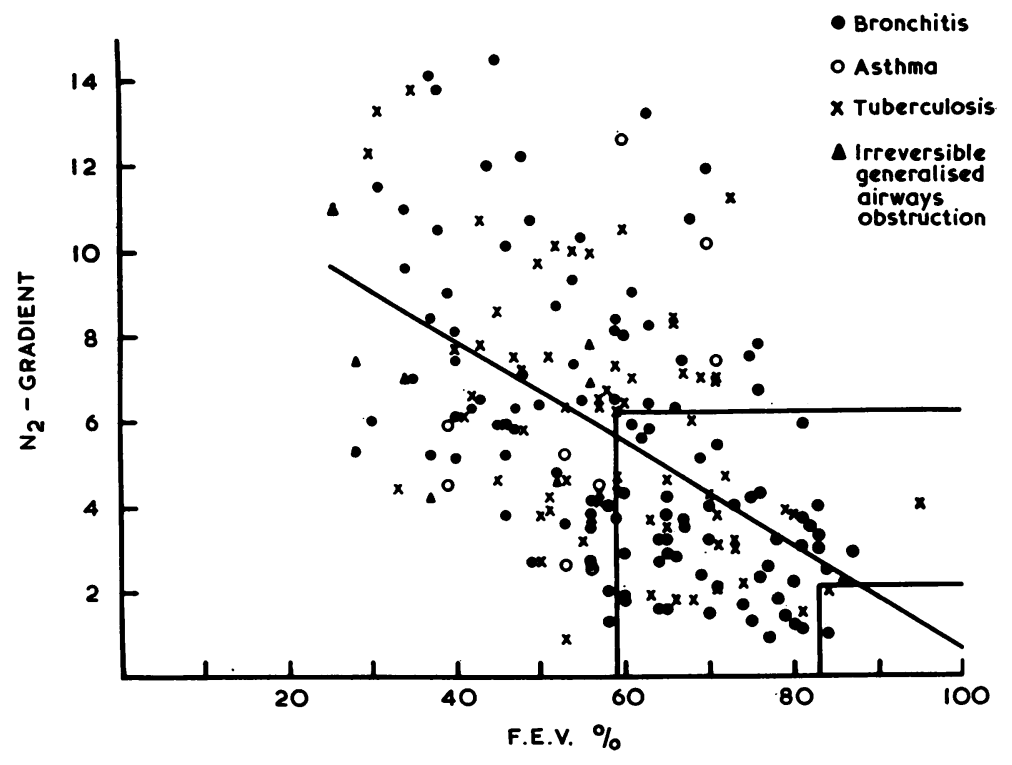

T A B LE

\begin{tabular}{|c|c|c|c|c|c|c|c|}
\hline \multirow[t]{2}{*}{ Diagnosis } & \multirow{2}{*}{$\begin{array}{l}\text { No. of } \\
\text { Patients }\end{array}$} & \multicolumn{2}{|c|}{ Pathological F.E.V.\% } & \multicolumn{2}{|c|}{ Normal F.E.V.\% } & \multirow{2}{*}{$\begin{array}{l}\text { Correlation } \\
\text { Coefficient }\end{array}$} & \multirow{2}{*}{$\begin{array}{l}\text { Significance } \\
P<0.001\end{array}$} \\
\hline & & $\begin{array}{l}\text { Pathological } \\
N_{2}\end{array}$ & $\begin{array}{l}\text { Normal } \\
N_{2}\end{array}$ & $\begin{array}{l}\text { Pathological } \\
\mathrm{N}_{2}\end{array}$ & $\begin{array}{l}\text { Normal } \\
\mathrm{N}_{2}\end{array}$ & & \\
\hline Bronchitis & 99 & 39 & 18 & 14 & 28 & -0.83 & + \\
\hline $\begin{array}{l}\text { Irreversible airways } \\
\text { obstruction } \\
\text { Asthma } \\
\text { Tuberculosis } \\
\text { Tumours } \\
\text { Pneumonectomy }\end{array}$ & $\begin{array}{r}7 \\
9 \\
67 \\
23 \\
13\end{array}$ & $\begin{array}{r}5 \\
2 \\
36 \\
4 \\
3\end{array}$ & $\begin{array}{r}2 \\
5 \\
15 \\
8 \\
3\end{array}$ & $\begin{array}{l}0 \\
2 \\
6 \\
2 \\
2\end{array}$ & $\begin{array}{r}0 \\
0 \\
10 \\
9 \\
5\end{array}$ & $\begin{array}{l}-0.40 \\
+0.47 \\
-0.50 \\
-0.17 \\
-0.48\end{array}$ & $\begin{array}{l}- \\
\pm \\
-\end{array}$ \\
\hline $\begin{array}{l}\text { Extrapulmonary } \\
\text { thoracic disease } \\
\text { Disseminated lung disease } \\
\text { Miscellaneous }\end{array}$ & $\begin{array}{l}10 \\
19 \\
17\end{array}$ & $\begin{array}{l}0 \\
3 \\
4\end{array}$ & $\begin{array}{l}1 \\
2 \\
3\end{array}$ & $\begin{array}{l}0 \\
7 \\
6\end{array}$ & $\begin{array}{l}9 \\
7 \\
4\end{array}$ & $\begin{array}{l}-0.70 \\
-0.01 \\
-0.39\end{array}$ & $\begin{array}{l}- \\
-\end{array}$ \\
\hline
\end{tabular}


In the other groups contrariwise, no relation was found between a pathological F.E.V. $\%$ and a pathological $\mathrm{N}_{2}$-gradient. Of interest is the finding that the patients with extrapulmonary restriction of lung movement (thoracic malformations and pleuritis) all showed a normal $\mathrm{N}_{2}$-test.

\section{DISCUSSION}

In this study two tests have been performed in order to evaluate the frequency of coincidence of airways obstruction and uneven gas distribution within the lungs.

An explicit theoretical and experimental review of the mechanical background for uneven gas distribution in the lungs has been published by Otis et al. (1956). It is theoretically likely that the patients with peripheral airways obstruction will show a high incidence of uneven gas distribution. This was also found to be the case in three of the groups studied, as shown in the Table.

There are, however, several reasons why there may not be a perfect linear relation between pairs of numerical values obtained from these two tests, showing in the plot as a wide scatter of values around the 'regression line' (Fig. 1). The two tests could not be performed simultaneously. Furthermore, the degree of anatomic disturbance (obstruction) does not relate linearly to either of the two tests. In fact complete obstruction of airways may 'exclude' certain lung portions from contributing to these tests; administration of bronchodilating agents in patients with airways obstruction often leads to improvement of the F.E.V.\% together with further impairment of the $\mathrm{N}_{2}$-gradient (Simonsson, to be published). Variations in the degree of airways obstruction may occur, due not only to the time lapse but also to the fact that one test is performed using a forced expiration (F.E.V.\%) and one using a relatively slow expiration ( $\mathrm{N}_{\mathrm{y}}$-test). Maximal inspiration, as used in one of the tests, also influences airways obstruction (Nadel and Tierney, 1961).

As has already been mentioned, there was a 2/1 incidence of pathological F.E.V. $\%$ to abnormal distribution in the bronchitis and tuberculosis groups (Table; Fig. 1). This agreement conceivably reflects airways obstruction in the tuberculous subjects, a diagnosis which of course is not excluded by the present classification. The high incidence of ventilatory obstruction in subjects with tuberculosis is in agreement with the finding of Gaensler and Lindgren (1959).

In bronchitics with a normal F.E.V. $\% 33 \%$ showed pathological $\mathrm{N}_{2}$-gradients which suggests a slight airways obstruction, which was not discernible with the spirometric method, but was revealed by the more sensitive single breath nitrogen test. The obstruction may be due to secretion in small airways or to bronchospasm. The reverse combination, a pathological F.E.V. $\%$ correlated with a normal $\mathrm{N}_{2}$-gradient, which occurred in $32 \%$ of the bronchitics with a low F.E.V. $\%$, may be due to a synchronous emptying or occlusion of airways, which otherwise would contribute with asynchronous emptying. The low F.E.V.\% may further depend on a collapse of larger airways during the forced expiration, as discussed above.

In the remaining groups shown in the Table there is no significant correlation between $\mathrm{N}_{2}$-gradient and F.E.V.\%. For the irreversible airways obstruction and asthma groups this may be explained by the small number of patients studied. It may also be due to increased narrowing of the airways during forced expiration, rendering the F.E.V.\% pathological. During quiet breathing, however, the airways remain open, and thus the $\mathrm{N}_{2}$-gradient may remain normal; the same has been found to be the case with R.V./T.L.C. ratios (Simonsson, to be published). The tumour cases all showed on bronchoscopy a partial obstruction of a central bronchus; the preponderance of normal $\mathrm{N}_{2}$-tests obtained may indicate that central obstruction does not greatly influence the alveolar gas distribution. In one case a pedicled tumour was seen to move in the bronchial lumen during the respiratory cycle, and there was a varying degree of obstruction and distribution $\left(\mathrm{N}_{2}\right.$-gradient 4.6 to $10.2 \%$ in three consecutive tests).

A wide-scale examination of patients who had undergone pneumonectomy has lately been performed in this laboratory and will be published separately (Birath et al., to be published). The patients with 'disseminated lung disease' show a relatively high incidence of pathological $\mathrm{N}_{2}$-tests. This may be due to local variations in the lung compliance, which will influence alveolar air distribution (Otis et al., 1956).

At suspected pathological values of F.E.V. $\%$ or in the pre-operative evaluation of tuberculosis and tumour cases it may be helpful to do a single breath nitrogen test with or without administration of bronchodilators. A pathological $\mathrm{N}_{2}$-gradient will make the presence of general airways obstruction likely. In this laboratory the single breath nitrogen test is often used for differentiating between generalized and localized partial obstruction of the airways.

\section{SUMMARY}

In 264 patients with various lung diseases the degree of airways obstruction was judged from the 
ratio of forced one-second volume to forced vital capacity (F.E.V.\%), and the unevenness of ventilation was assessed by the 'single breath nitrogen' method.

In the patients with bronchitis, irreversible airways obstruction, and lung tuberculosis a relation between these two tests was found. Twothirds of these patients who had a decreased F.E.V.\% likewise had a pathological $\mathrm{N}_{2}$-gradient. In one-third of the non-obstructive bronchitics the distribution was nevertheless pathological, probably due to slight airways obstruction not detected by the spirometric method.

\section{REFERENCES}

Berglund, E., Birath, G., Bjure, J., Grimby, G., Kjellmer, J., Sandqvist, L., and Söderholm, B. (1963). Acta med. scand., 173, 185. Bernstein, L., d'Silva, J. L., and Mendel, D. (1952). Thorax, 7, 255. Ciba Guest Symposium (1959). Ibid., 14, 286.

Drutel, P., and Dechoux, J. (1952). J. franc. Med. chir. thor., 6, 517. Fletcher, C. M. (1961). In Bronchitis, An International Symposium, 1960, Groningen, p. 273. Ed. Orie, N. G. M., and Sluiter, H. J. Royal Vangorcum, Assen, Netherlands.

Fowler, W. S. (1952). Physiol. Rev., 32, 1.

Gaensler, E. A., and Lindgren, I. (1959). Amer. Rev. resp. Dis., 80, No. 1, Pt. 2, p. 185.

Gandevia, B., and Hugh-Jones, P. (1957). Thorax, 12, 290.

Kjellmer, I., Sandqvist, L., and Berglund, E. (1959). J. appl. Physiol., 14, 105.

Nadel, J. A., and Tierney, D. F. (1961). Ibid., 16, 717.

Otis, A. B., McKerrow, C. B., Bartlett, R. A., Mead, J., McIlroy, M. B., Selverstone, N. J., and Radford, E. P. (1956). Ibid., 8, 427. Sandqvist, L., and Kjellmer, I. (1960). Scand. J. clin. Lab. Invest., 12,131 .

Thomson, W. B., and Hugh-Jones, P. (1958). Brit. med. J., $1,1093$. 